\title{
A rational use of glucocorticoids in patients with early arthritis has a minimal impact on bone mass
}

Monica Ibañez ${ }^{1}$, Ana M Ortiz², Isabel Castrejón², J Alberto García-Vadillo², Inmaculada Carvajal ${ }^{3}$, Santos Castañeda², Isidoro González-Álvaro ${ }^{2^{*}}$

\begin{abstract}
Introduction: Glucocorticoid (GC)-induced osteoporosis is a frequent complication in patients with rheumatoid arthritis. However, little information exists about the consequences of GC use in patients with early arthritis. Here we describe the variables underlying the use of GC in early arthritis, as well as its effect on bone-mineral density.

Methods: Data from 116 patients in our early arthritis register were analyzed (90 women; median age, 52.5 years, interquartile range (IQR, 38.5-66); 6-month median disease duration at entry (IQR, 4-9)). In this register, the clinical and treatment information was recorded systematically, including the cumulative GC dose. Lumbar spine, hip, and forearm bone-mineral density (BMD) measurements were performed at entry and after a 2-year follow-up.

A multivariate analysis was performed to establish the variables associated with the use of GCs, as well as those associated with variations in BMD.
\end{abstract}

Results: Of the patients with early arthritis studied, 67\% received GCs during the 2-year follow-up. GCs were more frequently prescribed to elderly patients, those with higher basal disease activity and disability, and patients with positive rheumatoid factor. When adjusted for these variables, GCs were less frequently prescribed to female patients. The use of GCs was associated with an increase of BMD in the ultradistal region of the forearm, although it induced a significant loss of BMD in the medial region of the forearm. No relevant effect of GC was noted on the BMD measured at other locations.

Conclusions: The frequent use of GCs as a "bridge therapy" in patients with early arthritis does not seem to be associated with relevant loss of bone mass. Moreover, cumulative GC administration might be associated with an increase of juxtaarticular BMD.

\section{Introduction}

Rheumatoid arthritis (RA) is a systemic and chronic inflammatory disease that has been associated with disability, the existence of comorbidities, and decreased life expectancy [1,2]. The use of glucocorticoids (GCs) to treat RA offers rapid antiinflammatory effects and the capacity to arrest radiologic progression [3-6]. However, long-term GC use may cause multiple adverse events, even at low doses $[7,8]$. Therefore, an individual evaluation is required to establish the best risk/benefit ratio for their prescription $[9,10]$.

\footnotetext{
* Correspondence: isidoro.ga@ser.es
${ }^{2}$ Rheumatology Department, Hospital Universitario de La Princesa, Diego de

* Correspondence: isidoro.ga@ser.es
${ }^{2}$ Rheumatology Department, Hospital Universitario de La Princesa, Diego de León 62, Madrid, 28006, Spain
}

(c) 2010 Monica Ibañez et al.; licensee BioMed Central Ltd. This is an open access article distributed under the terms of the Creative

One of the most striking side effects of this drug is GC-induced osteoporosis (GIOP), a complication in patients with RA that can be prevented [11-13]. The prevalence of OP in RA patients is higher than that in the normal population, ranging from $20 \%$ to $37 \%$ $[14,15]$, although this figure increases to almost $50 \%$ among postmenopausal women after long-term steroid use [16]. However, establishing the real contribution of GCs to OP in RA is challenging because bone mineral loss is of multifactorial origin in these patients, and it may be influenced by inflammatory cytokines, inactivity, GCs, disease-modifying antirheumatic drugs (DMARDs), as well as the classic risk factors for OP. 
Despite the different studies focusing on OP, little information is available regarding the use of GCs in patients with early arthritis. Nevertheless, it has been suggested that using GC in these patients does not affect bone mass, as has been observed in the long-term disease, probably because controlling inflammatory activity at early stages may prevent bone loss [17-19].

The aim of this study was to analyze the patterns of GC use and the reasons for its use in a population of early arthritis patients. In addition, we studied the impact of different factors on the evolution of mineral bone content in these patients, including GC use.

\section{Materials and methods}

\section{Patients and study design}

We studied 116 patients who attended our Early Arthritis Clinic from July 2002 to April 2008. Patients were referred to the clinic if they had two or more swollen joints for $\geq 4$ weeks and symptoms for $<1$ year. Patients were excluded if diagnosed with gouty arthritis, septic arthritis, spondyloarthropathies, or connective tissue diseases during the follow-up period. In addition, we excluded patients with primary hyperparathyroidism and other metabolic bone disorders other than OP. At the end of the follow-up period, 78 patients fulfilled the ACR 1987 criteria for RA classification [20], and 38 patients were classified as having undifferentiated arthritis (UA). The characteristics of the patients are shown in Table 1. The study protocol was reviewed and approved by the Local Research Ethics Committee, and all the patients who entered the study signed a written consent form after being informed about the details of the protocol.

The study includes data from patients followed up over a period of 2 years and who were evaluated at four visits during this period. The following data were collected and entered into an electronic database: clinical and demographic information, including the 28 tender and swollen joint counts (TJCs and SJCs, respectively); global disease assessment by patient (GDAP) and physician (GDAPh) on a $100-\mathrm{mm}$ visual analogue scale; and basic laboratory tests including erythrocyte sedimentation rate (ESR), C-reactive protein (CRP), rheumatoid factor (RF: by nephelometry; positive if $>20 \mathrm{IU} / \mathrm{ml}$ ), and serum antibodies directed against cyclic citrullinated peptide (anti-CCP: ELISA, Euro-Diagnostica Immunoscan RA; positive at $>50 \mathrm{IU} / \mathrm{ml}$ ). The four-component disease-activity score based on 28-joint counts and ESR (DAS28) was calculated as described previously [21]. The patients also completed the validated Spanish version of the Health Assessment Questionnaire (HAQ) to assess functional ability [22].

Comorbidity of other medical conditions was evaluated during the follow-up period, including that of hypertension, diabetes mellitus, and thyroid dysfunction. Other known factors that affect bone mass were also

Table 1 Baseline population characteristics

\begin{tabular}{|c|c|c|c|c|}
\hline & Total $(n=116)$ & $\mathrm{RA}(\mathrm{n}=78)$ & UA $(n=38)$ & $P$ \\
\hline Age & $52.5[38.5-65.6]$ & $51.6[43.0-66.7]$ & $53.5[34.0-64.5]$ & NS \\
\hline Female gender, $n$ (\%) & $90(77.6)$ & $63(80.7)$ & $27(71.1)$ & NS \\
\hline Disease duration (mo) & $6.1[4.2-9.1]$ & $5.6[4.0-8.4]$ & $6.75[4.5-9.8]$ & NS \\
\hline HAQ & $1.0[0.5-1.5]$ & $1.1[0.5-1.6]$ & $0.8[0.5-1.3]$ & NS \\
\hline DAS28 & $3.9[3.2-5.2]$ & $4.5[3.6-5.8]$ & $3.3[2.8-4.6]$ & 0.001 \\
\hline Rheumatoid factor, $n$ (\%) & $45(38.8)$ & $38(48.7)$ & $7(18.4)$ & 0.002 \\
\hline Anti-CCP, $n(\%)$ & $39(33.6)$ & $36(46.1)$ & $3(7.9)$ & $<0.001$ \\
\hline \multicolumn{5}{|l|}{ Comorbidities: $n$ (\%) } \\
\hline Hypertension & $35(30.2)$ & $22(28.2)$ & $13(34.2)$ & NS \\
\hline Diabetes mellitus & $13(11.2)$ & $8(10.2)$ & $5(13.2)$ & NS \\
\hline Thyroid dysfunction & $17(14.6)$ & $15(19.2)$ & $2(5.2)$ & 0.1 \\
\hline Menopause (\% of women) & 58 & 59 & 56 & NS \\
\hline Age at menopause (years) & 50 [44-52] & $48[44-50]$ & $52[50-53]$ & 0.017 \\
\hline $\begin{array}{l}\text { Calcium intake } \\
\text { (rare/moderate/high), (\%) }\end{array}$ & $15 / 62 / 23$ & $14 / 65 / 21$ & $16 / 58 / 26$ & NS \\
\hline Smoking $n(\%)$ & $28(24.1)$ & $19(24.4)$ & $9(23.7)$ & NS \\
\hline Exercise (rare/moderate/intense) (\%) & $38 / 47 / 15$ & $42 / 42 / 16$ & $29 / 58 / 13$ & NS \\
\hline Body mass index $\left(\mathrm{kg} / \mathrm{m}^{2}\right)$ & $26.5[24.5-30.5]$ & $26.0[24.0-30.0]$ & $28.0[26.0-30.9]$ & NS \\
\hline Prior personal fractures (\%) & 17 & 18 & 16 & NS \\
\hline Prior family fractures (\%) & 19 & 18 & 24 & NS \\
\hline
\end{tabular}

Data are shown as the percentage of patients or as the median and interquartile range.

Abbreviations: anti-CCP, antibodies directed to cyclic citrullinated peptide; DAS28, disease activity score in 28 joints; HAQ, health assessment questionnaire; NS, not statistically significant; RA, rheumatoid arthritis; UA, undifferentiated arthritis. 
assessed, such as body mass index (BMI) expressed in kilograms per square meter, age at menopause, daily calcium intake (0-500 mg, 500-1,000 mg, or >1,000 mg), exercise (sedentary, moderate, or intense aerobic exercise), smoking, and clinical fractures (vertebral, peripheral, or both) before inclusion in our register and during the follow-up period.

Information about disease-modifying antirheumatic drugs (DMARDs) treatment during the follow-up period, the dose of prednisone at each visit, and the cumulative GC dose (as a prednisone equivalent) also were obtained. Regarding the latter, we separately collected the cumulative dose of GCs prescribed orally and that administered as joint and soft-tissue injections (see Additional file 1 for further information). Most injections were performed in the knee or shoulder; no wrist injections were performed, although a few injections were administered into the small joints of the hand, mainly proximal interphalangeal.

\section{Bone-mineral density measurement}

Dual-energy $x$-ray absorptiometry (DXA) scans were performed on a Hologic QDR-4500/W Elite densitometer (Hologic Inc., Bedford, MA, USA), and the bone mineral density (BMD) was expressed in grams per square centimeter. Lumbar spine, hip, and nondominant forearm DXA scans were carried out at the patient's first (median disease duration, 7 months (IQR, 4-9)) and last visit in the study (median disease duration, 32.5 months (IQR, 29-35)). The densitometer was calibrated daily by using a quality assurance spine phantom of known bone mineral content (BMC) supplied by the manufacturer. The in vivo short-term coefficient of variation for our DXA machine was $0.9 \%$ for measurements at the lumbar spine level and $1.4 \%$ for the duplicate total hip measurements in 10 healthy subjects (data not shown).

We calculated the yearly variation in BMD at each location as follows: $\triangle \mathrm{BMD}=\left(\mathrm{BMD}_{\text {final }}-\mathrm{BMD}_{\text {baseline }}\right) \times$ $365 /$ number of days between both measurements. The results of these variables are presented as milligrams per square centimeter per year.

\section{Statistical analysis}

The descriptive analysis was performed by calculating the means and standard deviations (SDs) of quantitative variables with a gaussian distribution. The median and the interquartile range (IQR) were calculated if the variables did not display a normal distribution. An estimate of the proportions was calculated for qualitative variables. Unless otherwise stated, Student's $t$ test was applied to compare the means of variables with a normal distribution, and the Mann-Whitney or KruskallWallis tests were used for variables that did not have a normal distribution. Fisher's test was used to compare the categoric variables.

Because one third of the patients did not take GCs during the follow-up period, we used the zip command of Stata 9.2 for Windows (StataCorp LP, College Station, TX, USA) to analyze the cumulative dose of GCs. This command defines a zero-inflated Poisson regression that enables us to analyze both the reasons underlying the zero counts (no GCs prescribed) and those associated with the cumulative GC dose. All variables associated with a $P \leq 0.15$ in the bivariate analysis were included as independent variables, both to estimate the Poisson regression of the dependent variable (cumulative GC dose in milligrams per month) and in the inflate option of the zip command. This option specifies the equation that determines whether the observed count is zero. The final model was then reached by using stepwise backward estimates, removing all variables with $P>0.15$.

A generalized linear model was applied to assess the independent effect of different variables on the $\triangle B M D$ at the lumbar spine, hip, and forearm. We used the $\mathrm{glm}$ command of Stata 9.2 to define the linear regression of all the variables with a $P$ value $\leq 0.15$. The final model was then reached by using stepwise backward estimations, removing all variables with $P>0.15$. Subsequently, the cumulative GC dose was forced into the model to determine whether it affected the variation in BMD once the model was adjusted for the variables considered relevant. To assess whether oral and intraarticular/ soft tissue injection had equivalent effects on BMD, we also developed a model with two independent variables, one for the cumulative GC dose prescribed orally and another for the cumulative GC dose administered as soft-tissue and joint injections. However, this model did not provide more information than the model that included the effect of the global cumulative GC dose.

\section{Results}

\section{Description of the use of glucocorticoids}

Among our 116 patients, 38 (32.7\%) received GCs orally, $11(9.4 \%)$ received only soft-tissue injections, and 28 (24.3\%) were administered GCs by both routes during the follow-up period. Oral GC therapy was prescribed mostly as a bridging therapy, and it commenced at the first visit (Figure 1a), although about $11 \%$ of patients received the drug later in the follow-up. Thus, the prescription of GCs increased by $45.4 \%$ during the first 6 months, and then it gradually decreased to only $17.3 \%$ by the end of the follow-up period (Figure 1a). Doses of prednisone $>7.5 \mathrm{mg}$ /day were prescribed to $21.5 \%$ of patients at the baseline, although by the end of the study, only $3.7 \%$ of patients still received such high doses (Figure 1a and Additional file 2). The median cumulative $\mathrm{GC}$ dose in the whole population during the 
(a)

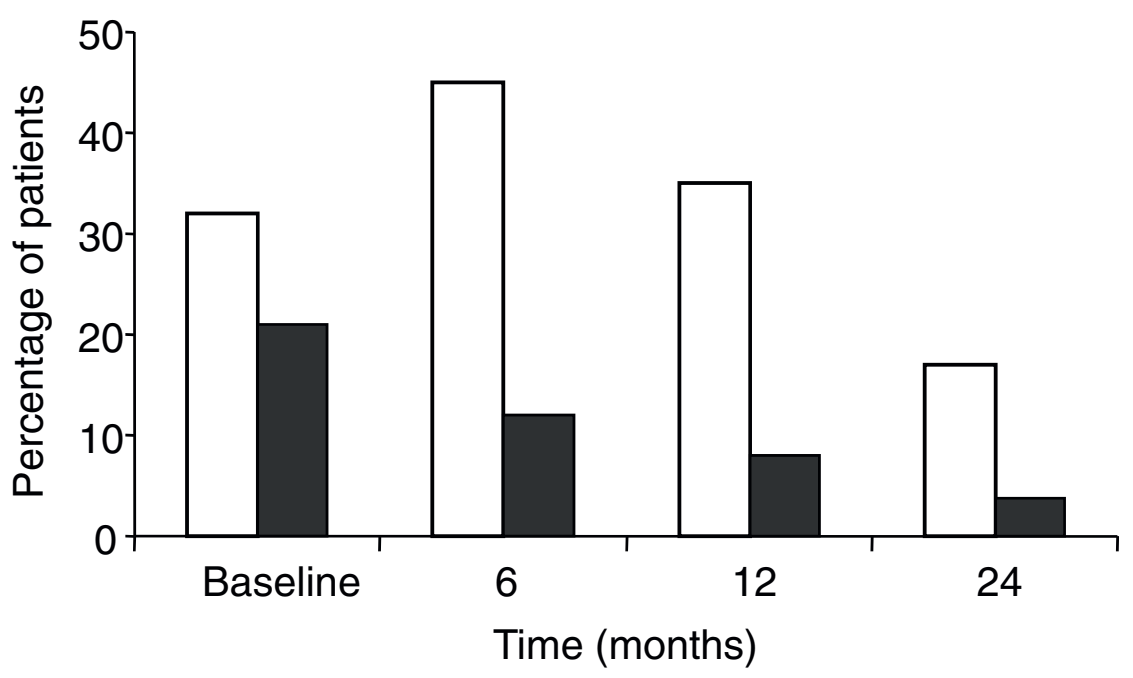

(b)

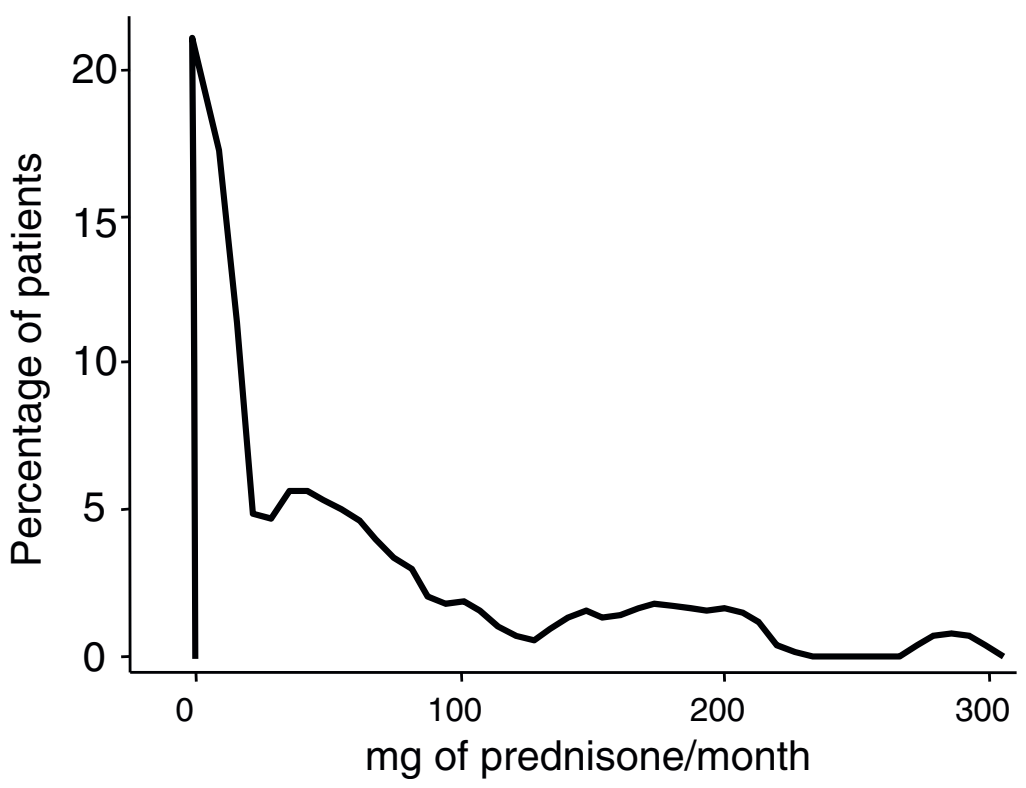

Figure 1 Use of glucocorticoids (GCs) in patients with early arthritis. (a) Percentage of patients that received GCs at each follow-up visit. White columns represent the percentage of patients receiving GCs; black columns represent the patients who received $>7.5 \mathrm{mg}$ of GC per day. (b) Distribution of cumulative GC dose adjusted to the duration of the follow-up in the whole population. The graph was obtained by using the kdensity command of Stata 9.2, which provides kernel density estimates of continuous variables in a population.

study was $865 \mathrm{mg}$ (IQR, 0-2,263), and when adjusted for the duration of the follow-up, it was $22 \mathrm{mg} / \mathrm{month}$ (IQR, 0-70) (Figure 1b). When only the patients that received GCs were considered, the median cumulative dose of GCs was $1,656 \mathrm{mg}(855-3,751)$ and $45 \mathrm{mg} /$ month (IQR, 21-106) when adjusted to the duration of the follow-up. More-extensive information on the use of GCs in our population is provided in Additional file 2.
The prescription of GCs was associated with male gender and the more-advanced age of the patients. In addition, a tendency was noted to prescribe GCs more frequently to those patients with a higher baseline DAS28 and HAQ, although this was not statistically significant in our cohort. In those patients who received GCs, the cumulative dose was significantly higher in men, in older patients, in those patients with 
seropositive arthritis or a worse functional status, in those with a higher disease activity at baseline, as well as in those treated with combined DMARD therapy. An inverse relation between cumulative GC dose and disease duration at baseline was also observed. Once adjusted for all these variables, patients with UA received higher doses of prednisone than did those with RA. More-extensive information on the motives underlying GC prescription and the cumulative GC dose is provided in Additional file 3.

\section{Effect of glucocorticoids on bone mass}

During the follow-up period, generally a significant decrease in BMD was noted at all sites, except for a significant increase in BMD detected in the total hip measurement. No significant variations were detected at the ultradistal and distal forearm (Figure 2).

Although we observed slight differences in the factors associated with the variation in bone mass at different locations, the variables that were globally associated with a significant decrease in BMD were menopause, diabetes, and thyroid disorders (Table 2). In addition, patients with higher disease activity displayed a trend toward a greater decrease in BMD at the lumbar spine, total hip, and ultradistal forearm, and the association of the mean DAS28 with BMD loss during follow-up was significant at the lumbar spine (Table 2). By contrast, BMD at the lumbar spine and the total hip BMD increased significantly in older patients (Table 2), which was probably related to osteoarthritis, as described previously $[23,24]$.
Interestingly, we observed a positive correlation between the cumulative dose of GCs and the variation in BMD at the ultradistal forearm (Figure 3, upper panel; $r=0.22, P=0.08$ ), although these parameters were negatively correlated at the mid-forearm (Figure 3, lower panel; $r=-0.2 ; P=0.11$ ). These findings were statistically significant in the multivariate analysis after adjustment for the independent variables described earlier (Table 2). Conversely, the cumulative dose of GCs did not seem to influence BMD significantly at the other sites analyzed (Table 2).

\section{Discussion}

The most intriguing finding in our study was that the use of GCs has no relevant impact on bone mass in patients with early arthritis. Earlier studies that focused on the effect of GCs on bone mass in patients with early arthritis maintained fixed low doses of GC for long periods, or alternatively, they involved a schedule that tapered the doses of these drugs from high to low doses and then withdrew the GC, or maintained it at low doses for a long period [18,25]. However, in our earlyarthritis clinic, no preestablished therapeutic protocol existed, and GCs were prescribed mainly as a bridging therapy in patients with more-severe forms of the disease, on average starting at $15 \mathrm{mg} /$ day of prednisone and then gradually tapering to its withdrawal $\sim 14$ months later. No more than $50 \%$ of patients received GCs orally, and only $17.3 \%$ of patients were under treatment with GCs at the end of the study. In addition, the prescription of the drug was adjusted to the profile of

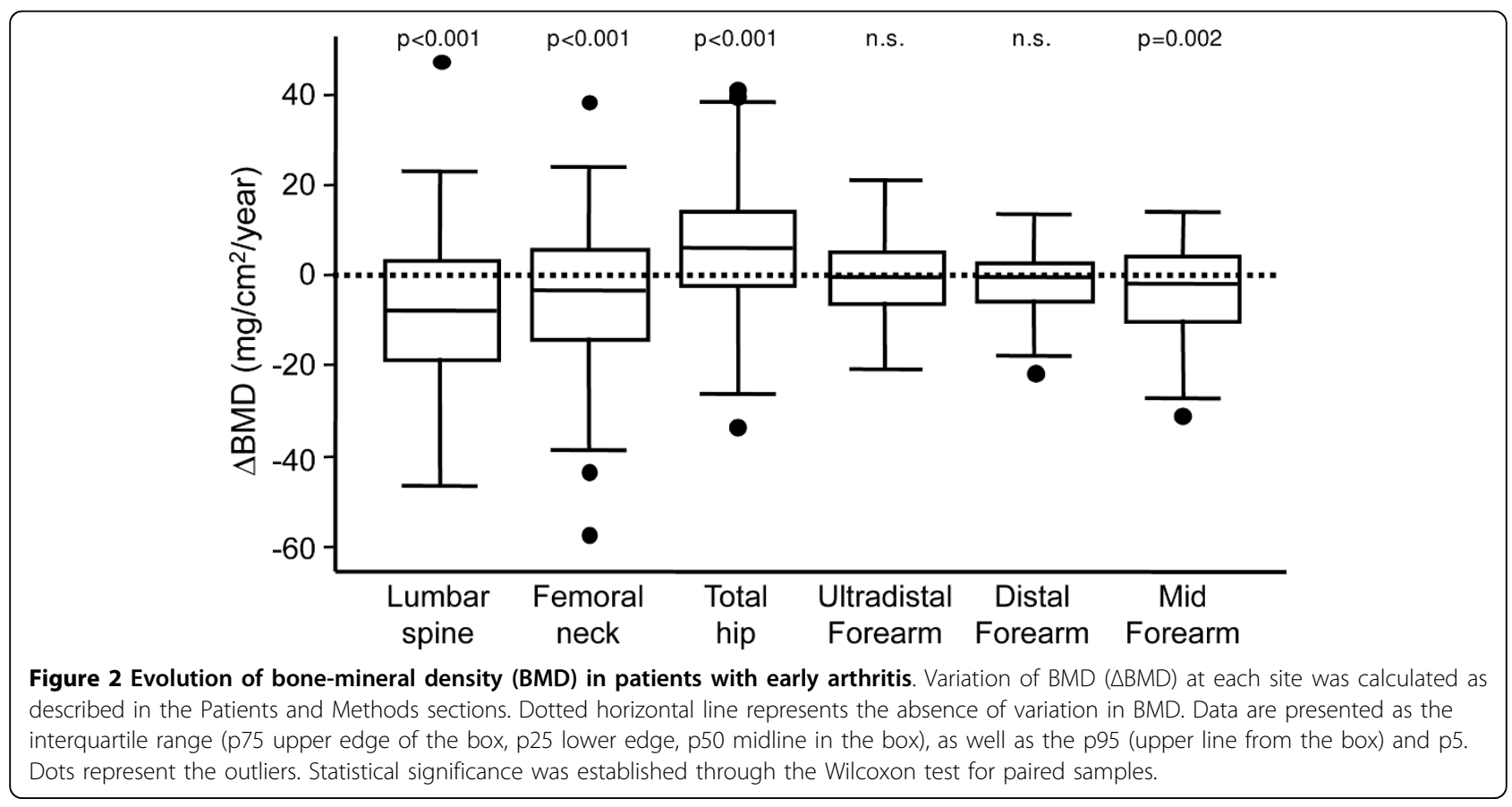


Table 2 Variables associated with the variation in bone-mineral density $\left(\mathrm{mg} / \mathrm{cm}^{2} / y e a r\right)$ at different sites in patients with early arthritis

\begin{tabular}{|c|c|c|c|c|c|c|c|c|c|c|}
\hline & \multicolumn{10}{|c|}{ Multivariate analysis } \\
\hline & \multicolumn{2}{|c|}{ Lumbar spine } & \multicolumn{2}{|c|}{ Total hip } & \multicolumn{2}{|c|}{ UD forearm } & \multicolumn{2}{|c|}{ D forearm } & \multicolumn{2}{|c|}{$M$ forearm } \\
\hline & Coeff \pm SD & $P$ & Coeff \pm SD & $P$ & Coeff \pm SD & $P$ & Coeff \pm SD & $P$ & Coeff \pm SD & $P$ \\
\hline Age (by year) & $0.3 \pm 0.1$ & 0.006 & $0.2 \pm 0.1$ & 0.026 & - & $\mathrm{NI}$ & - & NS & - & $\mathrm{NI}$ \\
\hline Female gender & - & NS & $6.1 \pm 3.6$ & 0.094 & $8.7 \pm 4.1$ & 0.032 & - & $\mathrm{NI}$ & - & NS \\
\hline Menopause & - & $\mathrm{NI}$ & - & $\mathrm{Nl}$ & $-6.4 \pm 3.3$ & 0.057 & $-3.5 \pm 1.4$ & 0.01 & - & $\mathrm{NI}$ \\
\hline Hypertension & $6.9 \pm 3.9$ & 0.081 & - & NS & - & $\mathrm{Nl}$ & - & NS & $6.7 \pm 3.6$ & 0.06 \\
\hline Diabetes & $-19.5 \pm 4.8$ & $<0.001$ & - & $\mathrm{NI}$ & - & $\mathrm{NI}$ & - & $\mathrm{NI}$ & $-10.3 \pm 5.3$ & 0.05 \\
\hline Thyroid dis. & $-13.7 \pm 3.9$ & $<0.001$ & - & $\mathrm{NI}$ & $-10.3 \pm 4$ & 0.01 & - & $\mathrm{NI}$ & - & $\mathrm{NI}$ \\
\hline Mean DAS28 & $-0.3 \pm 0.1$ & 0.042 & $-0.2 \pm 0.1$ & 0.141 & $-2.3 \pm 1.6$ & 0.145 & - & NS & - & $\mathrm{NI}$ \\
\hline $\begin{array}{l}\text { GC use } \\
(\mathrm{mg} / \mathrm{mo})\end{array}$ & $0.01 \pm 0.02$ & NS & $-0.01 \pm 0.02$ & NS & $0.05 \pm 0.02$ & 0.024 & $-0.001 \pm 0.009$ & NS & $-0.05 \pm 0.02$ & 0.025 \\
\hline
\end{tabular}

Abbreviations: D, distal; DAS28, disease activity score in 28 joints; M, medium; NS, not statistically significant; NI, not included in the analysis; Thyroid dis., thyroid disorders; UD, ultradistal.

comorbidity, the disease severity, and the patients' preferences. Thus, the prescription of GCs was more frequent in older patients (possibly related to the tendency to be less aggressive with DMARDs because of their higher comorbidity) and male patients (independent of age and disease activity), probably because women are more worried about the cosmetic side effects of GCs, and they reject high doses or long steroid treatments.

Unexpectedly, after adjustment for confounding factors in the multivariate analysis, patients with UA received more cumulative doses of GCs than did RA patients. This may reflect the preference in our center to use GCs instead of DMARDs in patients who do not meet ACR criteria for RA, at least during the first months of the follow-up.

The main variables associated with bone loss in patients with early arthritis are similar to those affecting the general population: the menopause and comorbidities such as diabetes or thyroid disorders. Interestingly, despite the limited number of patients in our study, we could detect an association between disease activity and bone loss in the lumbar spine, ultradistal forearm, and the total hip measurements, as suggested previously [26]. However, we did not find any relation between the annual variation of BMD and other factors such as calcium intake, exercise, smoking, personal or family history of fractures, or BMI (data not shown). The failure to demonstrate such a relation may reflect the limited number of patients, or perhaps, these factors may have less weight in the variation in bone mineral content in patients with arthritis than among the general population.

Intriguingly, a trend was noted toward higher bone mineral content in patients with hypertension at two of the sites where bone mass was measured. This increase might be related to the relatively high use of thiazides in association with renin-angiotensin antagonists in patients with hypertension in our country [27], particularly given that both kinds of drugs have been associated with improvements in BMD [28-31].

In accordance with previous studies in early arthritis, we did not find a significant correlation between cumulative doses of GCs and BMD variation at the lumbar spine or hip $[18,19,26]$. Nevertheless, our most relevant finding was at the forearm, where BMD has not previously been evaluated. We observed a clear association of the cumulative GC dose with an increase in BMD at the ultradistal forearm. This finding is probably related to the rapid and strong control of inflammation by GCs and most likely to its ability to arrest osteoclast function [32]. In this regard, GIOP was recently proposed to be mediated through the upregulation of a receptor activator for nuclear factor $\kappa \mathrm{B}$ ligand (RANKL) expression and the inhibition of osteoprotegerin expression [33-35]. However, with regard to RA synovitis, the levels of multiple cytokines with osteoclast-inducing activity, including RANKL, are elevated [36], and intraarticular GC decreases synovial RANKL expression [37]. This latter finding may be related to the increase in juxtaarticular BMD described here, which might also be associated with the ability of GC to impair joint destruction in early RA [25].

By contrast, moderate bone loss was found at the midforearm, where $95 \%$ is cortical bone. It is tempting to hypothesize that these effects might be explained by the development of secondary hyperparathyroidism due to the influence of GC on calcium metabolism [38,39]. Indeed, three patients had symptomatic fractures during follow-up (Additional file 4), two of which were peripheral fractures associated with cortical weakness.

One possible limitation of our study is the limited number of patients studied. However, we think that this deficit can be balanced by the exhaustive data collected in a highly controlled population. In addition, BMD was evaluated in six different anatomic locations. Thus, if we 

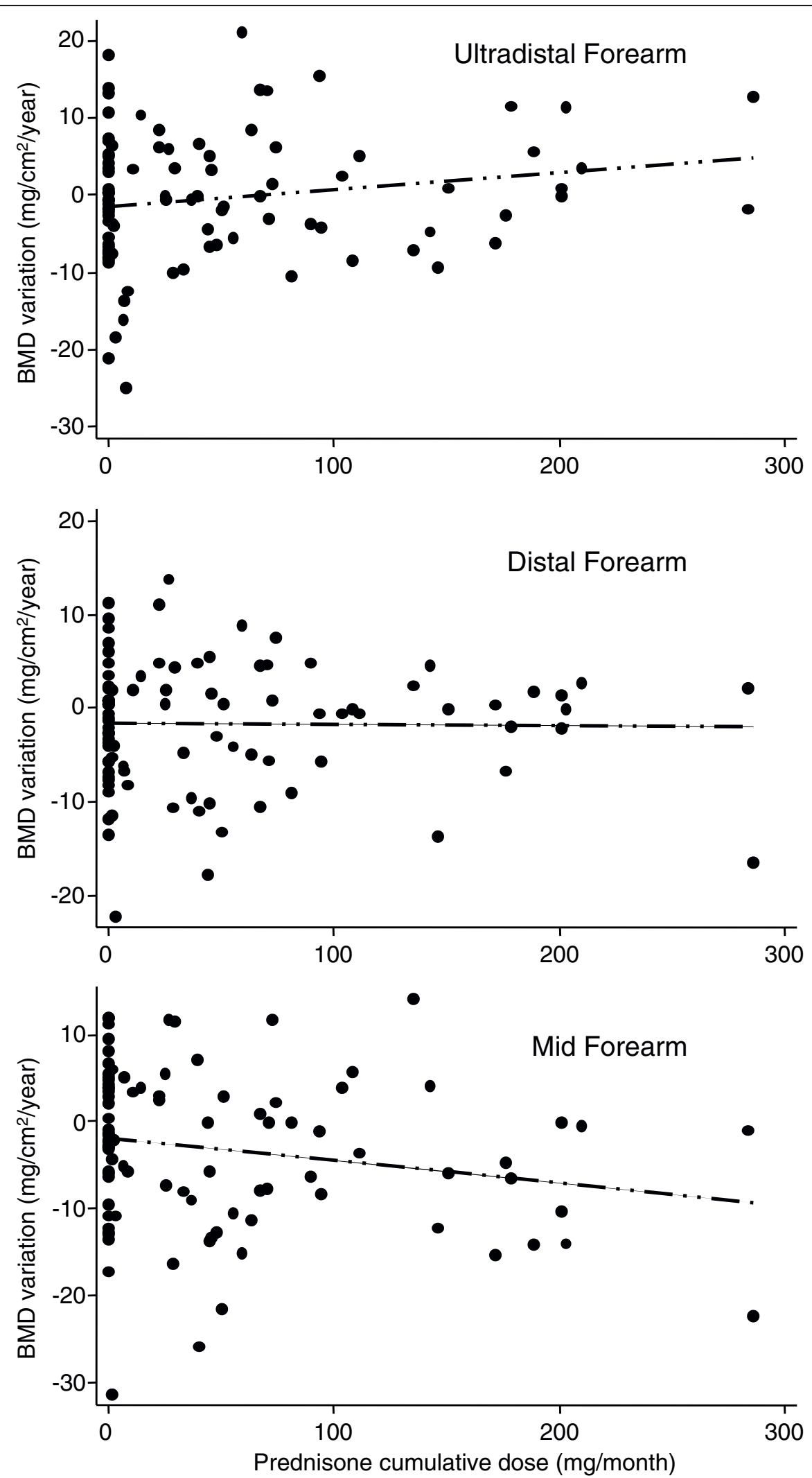

Figure 3 Correlation between cumulative doses of GC (mg/month) and the annual variation in BMD (mg/ $\mathrm{cm}^{2} / \mathrm{year}$ ). (a) $\mathrm{ultradistal,} \mathrm{(b)}$ distal, and (c) mid-forearm. Data are shown as dot plots and the estimated linear regression (dotted line). 
found a weak association at several locations, we could assume that it would have been less likely to have occurred by chance. It might also be argued that 2 years is a short period in which to study variations in BMD. However, it is well known that the effect of GC on bone mass occurs soon after exposure. It would have been interesting to measure BMD every 6 months during the follow-up period, although our schedule of BMD assessment was based on the follow-up recommendations for osteoporotic patients [40].

\section{Conclusions}

Among our patients with early arthritis, GCs were prescribed mainly as a bridge therapy to elderly patients, men, and patients with severe forms of the disease. This pattern of use, starting on average with $15 \mathrm{mg} / \mathrm{d}$ of prednisone and tapering toward withdrawal about 1 year later, does not seem to represent a relevant risk factor for bone loss. Furthermore, the cumulative GC dose correlated with an increase of juxtaarticular BMD, once adjusted for the classic variables associated with primary OP.

\section{Additional file 1: Intraarticular or soft-tissue glucocorticoid} injections: equivalencies in milligrams of prednisone. To calculate cumulative dose of glucocorticoids, doses corresponding to intraarticular and soft-tissue injections were estimated in milligrams of prednisone according to this table.

Additional file 2: Prescription of glucocorticoids in the population of early arthritis patients. These two tables provide detailed information regarding the characteristics of the population depending on the prescription of glucocorticoids and how this drug was used.

Additional file 3: Variables associated with glucocorticoid prescription and the cumulative dose of this drug by month of follow-up. Multivariate analysis that provides information about the variables that explain GC prescription and those associated with the cumulative dose of GC.

Additional file 4: Prescription of drugs for osteoporosis and the incidence of fractures during the follow-up. This file provides information about prevalence and variables associated with the prescription of drugs for osteoporosis. In addition, it describes the incidence of clinical fractures in the population described in the article.

\section{Abbreviations}

anti-CCP: serum antibodies directed to cyclic citrullinated peptide; BMD: bone-mineral density; DMARDs: disease-modifying antirheumatic drugs; GCs: glucocorticoids; GIOP: glucocorticoid-induced osteoporosis; OP: osteoporosis; RA: rheumatoid arthritis; RANKL: receptor activator for nuclear factor $\kappa \mathrm{B}$ ligand; RF: rheumatoid factor.

\section{Acknowledgements}

This work was funded by grants from the Instituto de Salud Carlos III: FIS 05/ 2044, to I G-A, and FIS 03/0911, to A G-V. The work of I G-A was funded in part by a grant to promote the research work in the Spanish National Health Service from the Instituto de Salud Carlos III (Programa de Intensificación de la Labor Investigadora).

\section{Author details}

'Rheumatology Department, Hospital Son Llàtzer, Carretera Manacor km. 4, Palma de Mallorca, 07198, Spain. ${ }^{2}$ Rheumatology Department, Hospital Universitario de La Princesa, Diego de León 62, Madrid, 28006, Spain.
${ }^{3}$ Rheumatology Unit, Hospital Nuestra Señora del Rosario, Príncipe de Vergara 53, Madrid, 28006, Spain.

\section{Authors' contributions}

MI participated in the acquisition and interpretation of the data and drafted the manuscript. AMO and I Castrejon participated in the data acquisition and helped to draft the manuscript. AG-V and SC participated in the design of the study and helped to draft the manuscript. I Carvajal participated in the data acquisition. IG-A participated in the design of the study and in the data acquisition, in the statistical analysis, in the interpretation of the data, and helped to draft the manuscript. All authors read and approved the final version of the manuscript submitted.

\section{Competing interests}

Over the past 5-year period, Dr. I. González-Álvaro has received unrestricted research funds from Abbott Laboratories, Sanofi-Aventis, and Bristol-Myers

Squibb. All these research projects bear no relation to this work.

Received: 23 July 2009 Revised: 20 November 2009

Accepted: 23 March 2010 Published: 23 March 2010

\section{References}

1. Sokka T, Abelson B, Pincus T: Mortality in rheumatoid arthritis: 2008 update. Clin Exp Rheumatol 2008, 26:S35-61.

2. Carmona L, Gonzalez-Alvaro I, Balsa A, Angel Belmonte M, Tena X, Sanmarti R: Rheumatoid arthritis in Spain: occurrence of extra-articular manifestations and estimates of disease severity. Ann Rheum Dis 2003, 62:897-900.

3. Jones G, Halbert J, Crotty M, Shanahan EM, Batterham M, Ahern M: The effect of treatment on radiological progression in rheumatoid arthritis: a systematic review of randomized placebo-controlled trials. Rheumatology (Oxford) 2003, 42:6-13.

4. Svensson B, Boonen A, Albertsson K, Heijde van der D, Keller C, Hafstrom I: Low-dose prednisolone in addition to the initial disease-modifying antirheumatic drug in patients with early active rheumatoid arthritis reduces joint destruction and increases the remission rate: a two-year randomized trial. Arthritis Rheum 2005, 52:3360-3370.

5. van Everdingen AA, Jacobs JW, Siewertsz Van Reesema DR, Bijlsma JW: Low-dose prednisone therapy for patients with early active rheumatoid arthritis: clinical efficacy, disease-modifying properties, and side effects: a randomized, double-blind, placebo-controlled clinical trial. Ann Intern Med 2002, 136:1-12.

6. Wassenberg S, Rau R, Steinfeld P, Zeidler H: Very low-dose prednisolone in early rheumatoid arthritis retards radiographic progression over two years: a multicenter, double-blind, placebo-controlled trial. Arthritis Rheum 2005, 52:3371-3380.

7. Caplan L, Wolfe F, Russell AS, Michaud K: Corticosteroid use in rheumatoid arthritis: prevalence, predictors, correlates, and outcomes. J Rheumatol 2007, 34:696-705.

8. McDonough AK, Curtis JR, Saag KG: The epidemiology of glucocorticoidassociated adverse events. Curr Opin Rheumatol 2008, 20:131-137.

9. Gonzalez-Alvaro I, Hernandez-Garcia C, Villaverde Garcia V, Vargas E, Ortiz AM: [Variations in the drug treatment of rheumatoid arthritis in Spain]. Med Clin (Barc) 2002, 118:771-776.

10. Thiele K, Buttgereit $F$, Huscher D, Zink A: Current use of glucocorticoids in patients with rheumatoid arthritis in Germany. Arthritis Rheum 2005, 53:740-747.

11. Curtis JR, Westfall AO, Allison J, Becker A, Melton ME, Freeman A, Kiefe Cl, MacArthur M, Ockershausen T, Stewart E, Weissman N, Saag KG: Challenges in improving the quality of osteoporosis care for long-term glucocorticoid users: a prospective randomized trial. Arch Intern Med 2007, 167:591-596

12. Solomon DH, Katz JN, La Tourette AM, Coblyn JS: Multifaceted intervention to improve rheumatologists' management of glucocorticoid-induced osteoporosis: a randomized controlled trial. Arthritis Rheum 2004, 51:383-387.

13. van Staa TP, Leufkens HG, Abenhaim L, Zhang B, Cooper C: Oral corticosteroids and fracture risk: relationship to daily and cumulative doses. Rheumatology (Oxford) 2000, 39:1383-1389.

14. Haugeberg G, Uhlig T, Falch JA, Halse Jl, Kvien TK: Bone mineral density and frequency of osteoporosis in female patients with rheumatoid 
arthritis: results from 394 patients in the Oslo County Rheumatoid Arthritis register. Arthritis Rheum 2000, 43:522-530.

15. Sinigaglia L, Nervetti A, Mela Q, Bianchi G, Del Puente A, Di Munno O, Frediani B, Cantatore F, Pellerito R, Bartolone S, La Montagna G, Adami S: A multicenter cross sectional study on bone mineral density in rheumatoid arthritis: Italian Study Group on Bone Mass in Rheumatoid Arthritis. J Rheumatol 2000, 27:2582-2589.

16. Nolla JM, Fiter J, Gomez Vaquero C, Mateo L, Valverde J, Roig Escofet D: [Study of bone mineral density in postmenopausal women with rheumatoid arthritis treated with low dose glucocorticoids]. Med Clin (Barc) 2000, 114:452-453.

17. Dolan AL, Moniz C, Abraha H, Pitt P: Does active treatment of rheumatoid arthritis limit disease-associated bone loss? Rheumatology (Oxford) 2002, 41:1047-1051

18. Guler-Yuksel M, Bijsterbosch J, Goekoop-Ruiterman YP, de Vries-Bouwstra JK, Hulsmans HM, de Beus WM, Han KH, Breedveld FC, Dijkmans BA, Allaart CF, Lems WF: Changes in bone mineral density in patients with recent onset, active rheumatoid arthritis. Ann Rheum Dis 2008, 67:823-828.

19. Habib GS, Haj S: Bone mineral density in patients with early rheumatoid arthritis treated with corticosteroids. Clin Rheumatol 2005, 24:129-133.

20. Arnett FC, Edworthy SM, Bloch DA, McShane DJ, Fries JF, Cooper NS, Healey LA, Kaplan SR, Liang MH, Luthra HS, et al: The American Rheumatism Association 1987 revised criteria for the classification of rheumatoid arthritis. Arthritis Rheum 1988, 31:315-324.

21. Prevoo ML, van 't Hof MA, Kuper $H H$, van Leeuwen $M A$, Putte van de $L B$, van Riel PL: Modified disease activity scores that include twenty-eightjoint counts: development and validation in a prospective longitudinal study of patients with rheumatoid arthritis. Arthritis Rheum 1995, 38:44-48.

22. Esteve-Vives J, Batlle-Gualda E, Reig A: Spanish version of the Health Assessment Questionnaire: reliability, validity and transcultural equivalency: Grupo para la Adaptacion del $\mathrm{HAQ}$ a la Poblacion Espanola. J Rheumatol 1993, 20:2116-2122.

23. Liu G, Peacock M, Eilam O, Dorulla G, Braunstein E, Johnston CC: Effect of osteoarthritis in the lumbar spine and hip on bone mineral density and diagnosis of osteoporosis in elderly men and women. Osteoporos Int 1997, 7:564-569.

24. Pye SR, Reid DM, Adams JE, Silman AJ, O'Neill TW: Radiographic features of lumbar disc degeneration and bone mineral density in men and women. Ann Rheum Dis 2006, 65:234-238.

25. Engvall IL, Svensson B, Tengstrand B, Brismar K, Hafstrom I: Impact of lowdose prednisolone on bone synthesis and resorption in early rheumatoid arthritis: experiences from a two-year randomized study. Arthritis Res Ther 2008, 10:R128.

26. Book C, Karlsson M, Akesson K, Jacobsson L: Disease activity and disability but probably not glucocorticoid treatment predicts loss in bone mineral density in women with early rheumatoid arthritis. Scand I Rheumatol 2008, 37:248-254.

27. Garcia del Pozo J, Ramos Sevillano E, de Abajo FJ, Mateos Campos R: [Use of antihypertensive drugs in Spain (1995-2001)]. Rev Esp Cardiol 2004, 57:241-249.

28. Asaba $Y$, Ito M, Fumoto $T$, Watanabe $K$, Fukuhara R, Takeshita S, Nimura $Y$, Ishida J, Fukamizu A, Ikeda K: Activation of renin-angiotensin system induces osteoporosis independently of hypertension. J Bone Miner Res 2009, 24:241-250.

29. Bolland MJ, Ames RW, Horne AM, Orr-Walker BJ, Gamble GD, Reid IR: The effect of treatment with a thiazide diuretic for 4 years on bone density in normal postmenopausal women. Osteoporos Int 2007, 18:479-486.

30. Lynn H, Kwok T, Wong SY, Woo J, Leung PC: Angiotensin converting enzyme inhibitor use is associated with higher bone mineral density in elderly Chinese. Bone 2006, 38:584-588.

31. Schoofs MW, Klift van der M, Hofman A, de Laet CE, Herings RM, Stijnen T, Pols HA, Stricker BH: Thiazide diuretics and the risk for hip fracture. Ann Intern Med 2003, 139:476-482

32. Kim HJ, Zhao H, Kitaura H, Bhattacharyya S, Brewer JA, Muglia LJ, Ross FP, Teitelbaum SL: Glucocorticoids suppress bone formation via the osteoclast. J Clin Invest 2006, 116:2152-2160.

33. Hofbauer LC, Gori F, Riggs BL, Lacey DL, Dunstan CR, Spelsberg TC, Khosla S: Stimulation of osteoprotegerin ligand and inhibition of osteoprotegerin production by glucocorticoids in human osteoblastic lineage cells: potential paracrine mechanisms of glucocorticoid-induced osteoporosis. Endocrinology 1999, 140:4382-4389.
34. Sivagurunathan S, Muir MM, Brennan TC, Seale JP, Mason RS: Influence of glucocorticoids on human osteoclast generation and activity. J Bone Miner Res 2005, 20:390-398.

35. Vidal NO, Brandstrom H, Jonsson KB, Ohlsson C: Osteoprotegerin mRNA is expressed in primary human osteoblast-like cells: down-regulation by glucocorticoids. J Endocrinol 1998, 159:191-195.

36. Goldring SR: Periarticular bone changes in rheumatoid arthritis: pathophysiological implications and clinical utility. Ann Rheum Dis 2009, 68:297-299.

37. Makrygiannakis D, af Klint E, Catrina SB, Botusan IR, Klareskog E, Klareskog L, Ulfgren AK, Catrina Al: Intraarticular corticosteroids decrease synovial RANKL expression in inflammatory arthritis. Arthritis Rheum 2006, 54:1463-1472.

38. Canalis E, Mazziotti G, Giustina A, Bilezikian JP: Glucocorticoid-induced osteoporosis: pathophysiology and therapy. Osteoporos Int 2007, 18:1319-1328.

39. Mazziotti G, Angeli A, Bilezikian JP, Canalis E, Giustina A: Glucocorticoidinduced osteoporosis: an update. Trends Endocrinol Metab 2006, 17:144-149.

40. El Maghraoui A, Roux C: DXA scanning in clinical practice. QJM 2008, 101:605-617.

doi:10.1186/ar2961

Cite this article as: Ibañez et al:: A rational use of glucocorticoids in patients with early arthritis has a minimal impact on bone mass. Arthritis Research \& Therapy 2010 12:R50.

\section{Submit your next manuscript to BioMed Central and take full advantage of:}

- Convenient online submission

- Thorough peer review

- No space constraints or color figure charges

- Immediate publication on acceptance

- Inclusion in PubMed, CAS, Scopus and Google Scholar

- Research which is freely available for redistribution 